\title{
Source and References
}

The above is a translation of De Groot's In Memoriam Allen Newell (1927-1992) as published in the NVKINieuwsbrief, Vol. 9. No. 4, pp. 116-117.

Groot, A.D. de (1946). Het denken van den schaker, een experimenteel-psychologische studie. Ph.D. thesis, University of Amsterdam; N.V. Noord-Hollandse Uitgevers Maatschappij, Amsterdam. Translated, with additions, (in 1965) as Thought and Choice in Chess. Mouton Publishers, The Hague.

Newell, A. (1983). The Heuristic of George Polya and its Relation to Artificial Intelligence. Methods of Heuristics (eds. R. Groner, M. Groner and W.F. Bishoff), pp. 195-243. Erlbaum, Hillsdale, N.J.

\section{LITERATURE RECEIVED}

\section{WISSENSDARSTELLUNG UND -VERARBEITUNG IN STRATEGISCHEN SPIELEN}

\author{
Christian Posthoff, Michael Schlosser and Rainer Staudte \\ Preprint Nr. 218/6. Jg./1992 \\ Fachbereich Informatik \\ Technische Universität Chemnitz \\ 21 pages
}

An English version of the abstract reads:

Strategic games (Draughts/Checkers, Chess, Go etc.) still are a major application area for AI methods, because the evaluation of results is as convenient as a risk-free experiment. Specifically one has to state, for the theories, algorithms and programs created, where they stand between the extremes of the algorithmic and descriptive concepts. The former is based on a small space requirement and intensive computing, the latter on high storage needs and relatively slight computing demands; any point in the spectrum between these extremes may nowadays be aimed at. In order to keep decisions subject to experts' judgement, concepts within the human window are to be preferred.

There is a natural stress in knowledge processing on the construction of rules which may be derived from aggregating single pieces of information. Several procedures for solving this problem are proposed. Applications are on positions in strategic games, for which extensive and generally-known experience is already available, which may not be true for less well-developed areas of knowledge.

\section{COMPUTER-CHESS ARTICLES PUBLISHED ELSEWHERE}

Matthew L. Ginsberg and William D. Harvey (1992). Iterative Broadening. Artificial Intelligence, Vol. 55, pp. 367-383.

\footnotetext{
Abstract - Conventional blind search techniques generally assume that the goal nodes for a given problem are distributed randomly along the fringe of the search tree. We argue that this is often invalid in practice and suggest that a more reasonable assumption is that decisions made at each point in the search carry equal weight. We go on to show that a new search technique called iterative broadening leads to orders-of-magnitude savings in the time needed to search a space satisfying this assumption; the basic idea is to search the space using artificial breadth cutoffs that are gradually increased until a goal is found. Both theoretical and experimental results are presented.
} 